\title{
Simulação de aldicarb e tebuthiuron movimento em solos sob cultivos de banana e cana-de-açúcar no semi-árido brasileiro
}

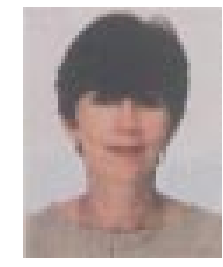

Maria C. P. Y. Pessoa ${ }^{1}$, Aldemir Chaim², Marco A. F. Gomes ${ }^{3}$, Aderaldo de S. Silva ${ }^{4} \&$ José M. Soares ${ }^{5}$

1 EMBRAPA Meio Ambiente. Rodovia SP340, km 127,5, CP 69, CEP 13820-000, Jaguariúna, SP. E-mail: young@cnpma.embrapa.br (Foto)

2 EMBRAPA Meio Ambiente. E-mail: aldemir@cnpma.embrapa.br

${ }^{3}$ EMBRAPA Meio Ambiente. E-mail: gomes@cnpma.embrapa.br

${ }^{4}$ EMBRAPA Meio Ambiente. E-mail: aderaldo@cnpma.embrapa.br

${ }^{5}$ EMBRAPA Semi-Árido. E-mail: sac@cpatsa.embrapa.br

Protocolo 44 - 18/4/2000 - Aprovado em 9/4/2002

\begin{abstract}
Resumo: Este trabalho apresenta resultados da tendência de movimento de tebuthiuron e aldicarb aplicados em cana-de-açúcar e banana respectivamente, no perfil vertical de solos de área da região Submédio São Francisco com lençóis subterrâneos encontrados a partir de 1,5 m de profundidade. Os solos analisados foram: Latossolo Amarelo Distrófico, Latossolo Amarelo Eutrófico, Latossolo Vermelho Eutrófico, Argissolo Vermelho-Amarelo Distrófico, Argissolo Vermelho-Amarelo Eutrófico, Argissolo Amarelo Álico, Argissolo Amarelo Distrófico, Argissolo Amarelo Eutrófico, Argissolo Acinzentado Álico, Planossolo Eutrófico, Neossolo Quartzarênico Distrófico e Neossolo Quartzarênico Álico. A movimentação foi acompanhada por simulação de sistemas para um período de três anos consecutivos, após uma única aplicação, em cenários separados por cultura e tipo de solo. Os resultados indicaram maior tendência de lixiviação de tebuthiuron e de aldicarb em Latossolo Vermelho Eutrófico, Neossolo Quartzarênico Distrófico e Neossolo Quartzarênico Álico. Não há indicativos de risco para a saúde humana, conforme padrão de referência da diretiva 89/778/EEC, para ambos os produtos nos cenários analisados.
\end{abstract}

Palavras-chave: simulação, qualidade da água, potencial de contaminação, impacto ambiental

\section{Simulation of aldicarb and tebuthiuron movement in soils under banana and sugarcane crops in the semi-arid region of Brazil}

\begin{abstract}
This study presents the results of the movement tendencies of the tebuthiuron and aldicarb applied to sugarcane and banana crops respectively, through the soil profile in an area of the 'Submédio São Francisco' region, where the sub-surface water was found at $1.50 \mathrm{~m}$ depth. The soils analyzed were: Distrophic Red Yellow Latosol (Typic Haplorthox); Eutrophic Yellow Latosol (Typic Eutrorthox); Eutrophic Red Yellow Latosol (Typic Eutrorthox); Distrophic Red Yellow Podzolic (Typic Kandiustults -Soil ); Eutrophic Red Yellow Podzolic (Typic Haplustults); Alic Yellow Podzolic (Typic Kandiustults); Distrophic Yellow Podzolic (Typic Kandiustults); Eutrophic Yellow Podzolic (Typic Haplustults); Alic Gray Podzolic (Typic Haplohumults); Eutrophic Planosol (Typic Albaquults); Distrophic Quartzous Sand (Typic Quartzipsament); Alic Quartzous Sand (Typic Quartzipsament). The movement of each product was followed by simulation during a period of three consecutive years after only one application of the pesticide, in separate scenarios for specific crop and soil type. The results showed main tendencies of tebuthiuron and aldicarb leaching in the Eutrophic Yellow Latosol, Distrophic Quartzous Sand and Alic Quartzous Sand. There were no indications of risk to human health according to the directive 89/778/EEC-reference level for both products in the analyzed scenarios.
\end{abstract}

Key words: simulation, water quality, potential of contamination, environmental impact

\section{INTRODUÇÃO}

A crescente conscientização da população para consumo de produtos agrícolas, originários de produções que não agridam a qualidade do meio ambiente, vem sendo um marco inibidor de mercados globalizados. Estão se formando nichos de consumidores, conscientes dos prejuízos à saúde e ao meio ambiente, que fiscalizam e balizam mercados, ao repudiarem produtos que não apresentam rastreabilidade da quantidade $\mathrm{e}$ qualidade de agroquímicos aplicados, particularmente de 
agrotóxicos e adubos minerais (Pessoa et al., 2002). Com o advento das normas ISO 9000 (BRASIL, 1996) e ISO 14000 (SEBRAE, 1998) surgiu a necessidade de se antecipar o potencial de risco de contaminação dos produtos e dos recursos naturais explorados no ambiente de seu cultivo (Silva et al., 2000). Por outro lado, a qualidade da água pode ser comprometida por agroquímicos aplicados em regiões onde os lençóis subterrâneos são rasos, como é o caso das zonas semiáridas nordestinas brasileiras (Ferracini et al., 2001; Cerdeira et al., 2000). Segundo a CODEVASF (1998) o período mais seco do ano nessa região está compreendido entre julho e outubro, quando são registrados os menores índices de precipitação pluviométrica. Também ressalta que esse, talvez, seja o principal motivo que inviabiliza o desenvolvimento e o aproveitamento agrícola das terras da região semi-árida brasileira, mas que pode ser superado pela proposição de uma infra-estrutura conveniente de irrigação, como aquelas registradas nos Distritos de Irrigação do Submédio São Francisco, nos quais a maior parte da área é destinada à produção irrigada de tomate, feijão, outras culturas temporárias, manga, uva, banana, goiaba, coco e cana-de-açúcar, em poucas áreas. Em geral, na região do Submédio São Francisco predomina a fruticultura irrigada, conduzida em grande escala, onde o uso de agrotóxicos é inevitável. Em conseqüência do aumento de quantidades produzidas, eleva-se cada vez mais a necessidade de uso de agrotóxicos, insumos e fertilizantes utilizados nas culturas, expondo a região ao risco de contaminação do ambiente entre outros problemas de impacto ambiental registrados na área. Assim sendo, torna-se imperativa a necessidade de monitorar o nível da qualidade dos recursos hídricos locais em função dos produtos aplicados nessas culturas, os quais, em movimento vertical nos solos da região, podem favorecer processos de lixiviação para camadas mais profundas do solo.

Os cultivos de banana e cana-de-açúcar são realizados nas áreas dos distritos de irrigação, em que predominam pequenos produtores. Muito embora a cana-de-açúcar não seja dominante, os efeitos residuais dos produtos aplicados podem ser analisados no ambiente semi-árido.

Uma das técnicas disponíveis para a realização de avaliação da dinâmica de produtos aplicados nas culturas no perfil vertical de solos é a simulação de sistemas (Pessoa et al., 1997). Esta técnica vem sendo amplamente utilizada em função do grande potencial de poluentes presentes em áreas de microbacias com atividade agrícola, cuja avaliação das conseqüências dessa atividade, em diferentes condições, demandaria grande esforço e gastos para coleta de informações (Pessoa et al., 1997). Entretanto, a relação custo x benefício, associada ao objetivo de estudo e a demanda de gastos para a utilização da ferramenta, deve ser avaliada no seu processo de escolha. O simulador "Chemical Movement in Layered Soils" CMLS-94 (Nofziger \& Hornsby, 1994) viabiliza a avaliação de potencial lixiviação e persistência de agrotóxicos em solo, muito embora não possibilite a avaliação de reaplicação do princípio ativo no mesmo cenário simulado. Exige baixo custo associado à obtenção dos dados de entrada necessários para utilizá-lo, propiciando, como resultados, os valores de profundidade e concentração no cenário do agrotóxico aplicado.
Assim sendo, o presente trabalho objetivou estudar a tendência de movimento vertical de aldicarb, um dos produtos aplicado na cultura da banana, e de tebuthiuron, empregado na cultura da cana-de-açúcar, em solos predominantes do Submédio São Francisco, visando analisar a dinâmica desses produtos para camadas inferiores do solo, dada a presença de lençóis subterrâneos na área a partir de 1,5 m de profundidade.

\section{MATERIAL E MÉTODOS}

\section{Simulador utilizado}

Foi utilizado o simulador "Chemical Movement in Layered Soils”- CMLS-94 (Nofziger \& Hornsby, 1994), que contempla um modelo matemático interativo, o qual estima o local de picos de concentração do princípio ativo do produto aplicado, assim como o seu movimento através do solo, em resposta ao movimento da água para maiores profundidades do solo e permite estimar a quantidade relativa do composto ainda no solo, em qualquer instante de tempo (durante a simulação).

O programa trabalha com até 20 camadas ou horizontes de solo, possibilitando que as propriedades do solo não sejam uniformes para todas as profundidades. As variáveis de solo consideradas para cada horizonte, são: a) profundidade do limiar inferior do horizonte; b) percentagem de carbono orgânico; c) densidade aparente; d) ponto de murcha; e) capacidade de campo, e f) saturação. As variáveis físicoquímicas são o coeficiente de partição normalizada para o conteúdo de carbono orgânico (Koc) e a meia vida de degradação no solo $\left(\mathrm{t}_{1 / 2}\right)$. Faculta ao usuário a entrada de coeficientes de partição para cada horizonte do solo, assim como especificar o tempo de meia vida para o composto no solo estudado, embora possua valores "default" médios de literatura em sua base de dados para ambos os parâmetros. Considera como variáveis climáticas a precipitação diária efetiva e a evapotranspiração diária, cujos resultados podem ser apresentados em forma de tabela ou gráfico, que permitem estimar a quantidade e profundidade atingida pelos agrotóxicos avaliados em diferentes períodos de tempo, durante o intervalo de simulação desejado.

\section{Área de estudo}

A região foco deste trabalho foi a região semi-árida brasileira, em particular aquela localizada no Submédio São Francisco, próximo a Petrolina, PE, em Latitude $9,24{ }^{\circ} \mathrm{S}$ e Longitude 40, $30^{\circ} \mathrm{W}$, com elevação de $375 \mathrm{~m}$.

Segundo informações da CODEVASF (1998), o forte impacto das variáveis climáticas sobre a região é particularmente observado no fato das drenagens locais da região serem naturalmente intermitentes.

\section{Dados de entrada}

Foram analisadas as culturas de cana-de-açúcar, tipo soqueira, e banana. Os dados solicitados pelo simulador para inclusão dessas culturas na base são os coeficientes culturais (Kc) das culturas, que representam a relação entre a evapotranspiração da cultura e a evapotranspiração de referência $\left(\mathrm{ET}_{0}\right)$ e/ou a evaporação do Tanque Classe "A", em cada estádio fenológico de desenvolvimento da cultura. Cada uma 
delas foi incorporada separadamente. As informações de Kc (Tabelas 1 e 2), relativas à cultura de cana-de-açúcar, foram obtidas em Paranhos (1987) (opção PLANALSUCAR) e aquelas relativas à cultura de banana por Soares \& Santos (1998).

Tabela 1. Valores do coeficiente cultural $(\mathrm{Kc})$ para a cultura de cana-de-açúcar (soqueira)

\begin{tabular}{clc}
\hline $\begin{array}{c}\text { Idade da } \\
\text { Cultura (dias) }\end{array}$ & \multicolumn{1}{c}{$\begin{array}{c}\text { Estádio de } \\
\text { Crescimento }\end{array}$} & $\begin{array}{c}\text { Valores de Kc } \\
(\mathrm{ETa} / \mathrm{ETb})\end{array}$ \\
\hline 1 & Plantio até 0,25 de fechamento & 0,50 \\
60 & 0,25 a 0,5 do fechamento & 0,65 \\
90 & 0,5 a 0,75 do fechamento & 0,75 \\
120 & 0,75 até fechamento & 0,90 \\
270 & Máximo desenvolvimento & 1,10 \\
300 & Início da maturação & 0,70 \\
360 & Maturação & 0,60 \\
\hline
\end{tabular}

Fonte: Paranhos (1987); ETa = Evapotranspiração real; ETb = Evapotranspiração basal

Tabela 2. Valores do coeficiente cultural $(\mathrm{Kc})$ para a cultura de banana

\begin{tabular}{cc}
\hline Idade da Cultura (dias) & Valores de Kc $(\mathrm{ETa} / \mathrm{ETb})$ \\
\hline 1 & 0,11 \\
62 & 0,70 \\
91 & 0,75 \\
121 & 0,70 \\
152 & 0,75 \\
182 & 0,85 \\
213 & 1,05 \\
244 & 1,20 \\
274 & 1,20 \\
305 & 1,20 \\
335 & 1,05 \\
Fonte: Soares \& Santos (1998); ETa = Evapotranspiração real; ETb= Evapotranspiração basal
\end{tabular}

Neste trabalho foram incluídas no simulador as principais características físicas dos solos predominantes no Submédio São Francisco (Tabela 3), próximos a Petrolina, PE, a saber: Latossolo Amarelo Distrófico, Latossolo Amarelo Eutrófico, Latossolo Vermelho Eutrófico, Argissolo Vermelho Amarelo Distrófico, Argissolo Vermelho Amarelo Eutrófico, Argissolo Amarelo Álico, Argissolo Amarelo Distrófico, Argissolo Amarelo Eutrófico, Argissolo Acinzentado Álico, Planossolo Eutrófico, Neossolo Quartzarênico Distrófico e Neossolo Quartzarênico Álico, conforme o sistema brasileiro de classificação de solos (EMBRAPA, 1999).

Para cada um deles foram fornecidas as seguintes informações: quantidade de horizontes e para cada um deles: a) profundidade (m); b) \% de carbono orgânico; c) densidade aparente $\left(\mathrm{Mg} \mathrm{m}^{-3}\right)$; d) conteúdo volumétrico de água (\%) para capacidade de campo, para o ponto de murcha e para a saturação.

Os dados climáticos foram fornecidos pela EMBRAPA SemiÁrido e posteriormente formatados, conforme demandado pelo simulador, e inseridos em arquivo. Referem-se a temperatura máxima, temperatura mínima, pluviosidade e evaporação diárias (dia juliano) para o período de três anos consecutivos.

Ambos os produtos foram utilizados em cenários de simulação específicos para avaliação do movimento de um único produto em um único solo, em cenários base fixos
Tabela 3. Valores de carbono orgânico (CO), densidade aparente (da) e o conteúdo volumétrico de água para capacidade de campo (CC), ponto de murcha permanente (PM) e saturação (S), para diferentes solos estudados

\begin{tabular}{|c|c|c|c|c|c|}
\hline \multirow{2}{*}{$\begin{array}{l}\text { Profundidade } \\
\qquad(\mathrm{cm})\end{array}$} & \multirow{2}{*}{$\begin{array}{l}\mathrm{CO} \\
(\%)\end{array}$} & \multirow{2}{*}{$\begin{array}{c}\mathrm{da} \\
\left(\mathrm{kg} \mathrm{dm}^{-3}\right)\end{array}$} & $\mathrm{CC}$ & PM & $\mathrm{S}$ \\
\hline & & & \multicolumn{3}{|c|}{$(\% \mathrm{~V})$} \\
\hline \multicolumn{6}{|c|}{ Latossolo Amarelo Distrófico } \\
\hline 14 & 0,62 & 1,51 & 8,2 & 3,7 & 16,4 \\
\hline 45 & 0,22 & 1,45 & 13,4 & 4,8 & 26,8 \\
\hline 110 & 0,22 & 1,48 & 12,9 & 4,9 & 25,8 \\
\hline 200 & 0,19 & 1,76 & 12,9 & 5,2 & 25,8 \\
\hline \multicolumn{6}{|c|}{ Latossolo Amarelo Eutrófico } \\
\hline 16 & 0,79 & 1,41 & 8,8 & 4,8 & 17,6 \\
\hline 40 & 0,28 & 1,46 & 12,9 & 5,4 & 25,8 \\
\hline 70 & 0,22 & 1,60 & 13,0 & 5,8 & 26,0 \\
\hline 110 & 0,24 & 1,48 & 11,2 & 6,9 & 22,4 \\
\hline 170 & 0,14 & 1,62 & 11,0 & 6,8 & 22,0 \\
\hline \multicolumn{6}{|c|}{ Latossolo Vermelho Eutrófico } \\
\hline 17 & 0,50 & 1,60 & 5,8 & 2,8 & 11,6 \\
\hline 45 & 0,17 & 1,44 & 7,1 & 3,1 & 14,2 \\
\hline 110 & 0,14 & 1,51 & 8,0 & 3,6 & 16,0 \\
\hline 200 & 0,14 & 1,71 & 11,2 & 4,7 & 22,4 \\
\hline \multicolumn{6}{|c|}{ Argissolo Vermelho Amarelo Distrófico } \\
\hline 17 & 0,69 & 1,46 & 8,8 & 4,1 & 17,6 \\
\hline 40 & 0,34 & 1,43 & 8,2 & 5,9 & 16,4 \\
\hline 90 & 0,28 & 1,62 & 8,9 & 6,7 & 17,8 \\
\hline 140 & 0,28 & 1,48 & 10,7 & 7,8 & 21,4 \\
\hline 190 & 0,22 & 1,38 & 14,7 & 10,4 & 29,4 \\
\hline \multicolumn{6}{|c|}{ Argissolo Vermelho Amarelo Eutrófico } \\
\hline 20 & 1,02 & 1,62 & 9,7 & 3,0 & 19,4 \\
\hline 45 & 0,36 & 1,35 & 10,9 & 7,2 & 21,8 \\
\hline 60 & 0,29 & 1,37 & 14,2 & 10,8 & 28,4 \\
\hline 120 & 0,29 & 1,34 & 18,5 & 14,7 & 37,0 \\
\hline 180 & 0,17 & 1,47 & 17,0 & 12,5 & 34,0 \\
\hline \multicolumn{6}{|c|}{ Argissolo Amarelo Álico } \\
\hline 20 & 0,74 & 1,64 & 7,1 & 2,6 & 14,2 \\
\hline 45 & 0,22 & 1,67 & 8,5 & 3,7 & 17,0 \\
\hline 120 & 0,19 & 1,67 & 14,2 & 5,2 & 28,4 \\
\hline 150 & 0,19 & 1,62 & 9,2 & 5,7 & 18,4 \\
\hline 200 & 0,17 & 1,64 & 9,3 & 5,7 & 18,6 \\
\hline \multicolumn{6}{|c|}{ Argissolo Amarelo Distrófico } \\
\hline 16 & 1,26 & 1,48 & 12,7 & 6,1 & 25,4 \\
\hline 40 & 0,50 & 1,46 & 10,5 & 7,5 & 21,0 \\
\hline 70 & 0,36 & 1,35 & 10,8 & 7,8 & 21,6 \\
\hline 130 & 0,28 & 1,45 & 13,0 & 8,8 & 26,0 \\
\hline 200 & 0,22 & 1,56 & 12,0 & 8,2 & 24,0 \\
\hline \multicolumn{6}{|c|}{ Argissolo Amarelo Eutrófico } \\
\hline 18 & 1,07 & 1,58 & 9,3 & 4,2 & 18,6 \\
\hline 40 & 0,41 & 1,47 & 11,1 & 7,2 & 22,2 \\
\hline 100 & 0,28 & 1,52 & 13,0 & 8,2 & 26,0 \\
\hline 140 & 0,22 & 1,48 & 13,5 & 9,7 & 27,0 \\
\hline 170 & 0,17 & 1,54 & 11,4 & 7,6 & 22,8 \\
\hline \multicolumn{6}{|c|}{ Argissolo Acinzentado Álico } \\
\hline 17 & 0,31 & 1,53 & 5,0 & 2,6 & 10,0 \\
\hline 37 & 0,26 & 1,57 & 9,2 & 4,0 & 18,4 \\
\hline 65 & 0,28 & 1,73 & 13,1 & 5,4 & 26,2 \\
\hline 100 & 0,22 & 1,70 & 12,8 & 5,3 & 25,2 \\
\hline \multicolumn{6}{|c|}{ Planossolo Eutrófico } \\
\hline 15 & 0,97 & 1,71 & 9,2 & 3,4 & 18,4 \\
\hline 40 & 0,50 & 1,73 & 9,7 & 3,7 & 19,4 \\
\hline 75 & 0,33 & 1,48 & 20,1 & 13,6 & 40,2 \\
\hline 105 & 0,40 & 1,45 & 22,0 & 15,4 & 44,0 \\
\hline 140 & 0,07 & 1,42 & 22,1 & 14,4 & 44,2 \\
\hline
\end{tabular}


Continuação da Tabela 3

\begin{tabular}{cccccr}
\hline $\begin{array}{c}\text { Profundidade } \\
(\mathrm{cm})\end{array}$ & $\begin{array}{c}\mathrm{CO} \\
(\%)\end{array}$ & $\begin{array}{c}\mathrm{da} \\
\left(\mathrm{kg} \mathrm{dm}^{-3}\right)\end{array}$ & $\mathrm{CC}$ & $\mathrm{PM}$ & \multicolumn{5}{c}{$\mathrm{S}$} \\
& \multicolumn{7}{c}{ Neossolo } & Quartzarênico Distrófico \\
16 & 0,66 & 1,65 & 4,6 & 2,3 & 9,2 \\
45 & 0,21 & 1,64 & 4,8 & 2,4 & 9,6 \\
100 & 0,14 & 1,60 & 5,9 & 2,5 & 11,8 \\
200 & 0,12 & 1,54 & 5,6 & 2,5 & 11,2 \\
\hline \multicolumn{7}{c}{ Neossolo Quartzarênico Álico } \\
17 & 0,24 & 1,74 & 3,9 & 1,3 & 7,8 \\
40 & 0,09 & 1,66 & 3,9 & 1,3 & 7,8 \\
90 & 0,09 & 1,58 & 4,2 & 1,7 & 8,4 \\
140 & 0,07 & 1,54 & 4,9 & 1,9 & 9,8 \\
180 & 0,10 & 1,72 & 7,4 & 2,2 & 14,8 \\
230 & 0,10 & 1,72 & 9,3 & 4,3 & 18,6 \\
\hline \multicolumn{7}{c}{}
\end{tabular}

relativos às culturas. Esses cenários base foram definidos como segue: a) cana-de-açúcar anual: aplicação única de $1,1 \mathrm{~kg} \mathrm{ha}^{-1}$ do herbicida tebuthiuron $\left(\mathrm{K}_{\mathrm{oc}}=46 \mathrm{~L} \mathrm{~kg}^{-1}, \mathrm{t}_{1 / 2}=365\right.$ dias$)$, aplicado em outubro e término de simulação três anos depois da aplicação do produto, sem reaplicações; b) banana: uma única aplicação de $30 \mathrm{~g}$ por cova do inseticida aldicarb, do grupo carbamato, que pertence à classe dos inseticidas, nematicidas e acaricidas $\left(\mathrm{K}_{\mathrm{oc}}=30 \mathrm{~L} \mathrm{~kg}^{-1} ; \mathrm{t}_{1 / 2}=30\right.$ dias $)$. Data de plantio em setembro e simulação para três anos consecutivos, sem reaplicações.

Os valores obtidos para concentração dos produtos, ao término das simulações, foram comparados aos estabelecidos para as recomendações da "Drinking Water Directive 89/778/ EEC" (Altenburger, 1993), para os valores referência de concentração máxima de agrotóxico admissível em água para consumo humano de $0,1 \mu \mathrm{g} \mathrm{L}^{-1}$ por substância e de $0,5 \mu \mathrm{g} \mathrm{L}^{-1}$ para a soma de compostos, dada a inexistência de valores referencia similares para o nosso país para os princípios ativos estudados.

\section{RESULTADOS E DISCUSSÃO}

\section{Cana-de-açúcar anual}

Os resultados obtidos pelas simulações realizadas para o herbicida tebuthiuron nos solos predominantes no Submédio do Rio São Francisco, próximos à região de Petrolina, PE, são apresentados na Tabela 4.

Pelos resultados (Tabela 4) para tebuthiuron em cana-deaçúcar, tem-se que:

a) primeiro ano: quantidade de produto presente no solo foi de $0,73 \mathrm{~kg} \mathrm{ha}^{-1}$; potencial para atingir profundidade de 1,00 m em Neossolo Quartzarênico Álico, 0,64 m em Neossolo Quartzarênico Distrófico e 0,60 m em Latossolo Vermelho Eutrófico. Entre os solos Podzólicos (nomenclatura antiga), a maior profundidade com potencial de ser atingida foi $0,497 \mathrm{~m}$, em Argissolo Acinzentado Álico;

b) segundo ano: quantidade de produto presente no solo foi de $0,36 \mathrm{~kg} \mathrm{ha}^{-1}$, com potencial de atingir profundidade de 3,10 m em Neossolo Quartzarênico Álico, 2,860 m em Neossolo Quartzarênico Distrófico e 2,01 m em Latossolo Vermelho Eutrófico. Entre os solos Podzólicos (nomenclatura antiga) a maior profundidade com potencial de ser atingida foi de 1,50 m, em Argissolo Vermelho Amarelo Distrófico;
Tabela 4. Valores de profundidades (Prof) e de quantidades (Qtd) de tebuthiuron encontradas ao final de cada ano de simulação em cada solo

\begin{tabular}{|c|c|c|}
\hline \multirow[b]{2}{*}{ Solo } & \multicolumn{2}{|c|}{ Tebuthiuron } \\
\hline & $\begin{array}{l}\text { Prof. } \\
\text { (m) }\end{array}$ & $\begin{array}{c}\text { Qtd } \\
\left(\mathrm{kg} \mathrm{ha}^{-1}\right)\end{array}$ \\
\hline \multicolumn{3}{|l|}{ A. Primeiro ano } \\
\hline Latossolo Amarelo Distrófico & 0,389 & 0,73 \\
\hline Latossolo Amarelo Eutrófico & 0,390 & 0,73 \\
\hline Latossolo Vermelho Eutrófico & 0,604 & 0,73 \\
\hline Argissolo Vermelho Amarelo Distrófico & 0,416 & 0,73 \\
\hline Argissolo Vermelho Amarelo Eutrófico & 0,240 & 0,73 \\
\hline Argissolo Amarelo Álico & 0,431 & 0,73 \\
\hline Argissolo Amarelo Distrófico & 0,238 & 0,73 \\
\hline Argissolo Amarelo Eutrófico & 0,290 & 0,73 \\
\hline Argissolo Acinzentado Álico & 0,497 & 0,73 \\
\hline Planossolo Eutrófico & 0,270 & 0,73 \\
\hline Neossolo Quartzarênico Distrófico & 0,640 & 0,73 \\
\hline Neossolo Quartzarênico Álico & 1,000 & 0,73 \\
\hline \multicolumn{3}{|l|}{$\begin{array}{ll}\text { B. Segundo ano } \\
\end{array}$} \\
\hline Latossolo Amarelo Distrófico & 1,347 & 0,36 \\
\hline Latossolo Amarelo Eutrófico & 1,468 & 0,36 \\
\hline Latossolo Vermelho Eutrófico & 2,010 & 0,36 \\
\hline Argissolo Vermelho Amarelo Distrófico & 1,500 & 0,36 \\
\hline Argissolo Vermelho Amarelo Eutrófico & 1,145 & 0,36 \\
\hline Argissolo Amarelo Álico & 1,480 & 0,36 \\
\hline Argissolo Amarelo Distrófico & 1,200 & 0,36 \\
\hline Argissolo Amarelo Eutrófico & 1,290 & 0,36 \\
\hline Argissolo Acinzentado Álico & 1,394 & 0,36 \\
\hline Planossolo Eutrófico & 0,970 & 0,36 \\
\hline Neossolo Quartzarênico Distrófico & 2,860 & 0,36 \\
\hline Neossolo Quartzarênico Álico & 3,100 & 0,36 \\
\hline \multicolumn{3}{|l|}{$\begin{array}{ll}\text { C. Terceiro ano }\end{array}$} \\
\hline Latossolo Amarelo Distrófico & 1,701 & 0,18 \\
\hline Latossolo Amarelo Eutrófico & 2,022 & 0,18 \\
\hline Latossolo Vermelho Eutrófico & 2,775 & 0,18 \\
\hline Argissolo Vermelho Amarelo Distrófico & 2,180 & 0,18 \\
\hline Argissolo Vermelho Amarelo Eutrófico & 1,660 & 0,18 \\
\hline Argissolo Amarelo Álico & 2,070 & 0,18 \\
\hline Argissolo Amarelo Distrófico & 1,780 & 0,18 \\
\hline Argissolo Amarelo Eutrófico & 1,920 & 0,18 \\
\hline Argissolo Acinzentado Álico & 1,855 & 0,18 \\
\hline Planossolo Eutrófico & 1,370 & 0,18 \\
\hline Neossolo Quartzarênico Distrófico & 4,350 & 0,18 \\
\hline Neossolo Quartzarênico Álico & 4,300 & 0,18 \\
\hline
\end{tabular}

Prof. = Profundidade; Qtd $=$ Quantidade de produto

c) terceiro ano: quantidade de produto ainda presente no solo foi de $0,18 \mathrm{~kg} \mathrm{ha}^{-1}$; com potencial para atingir a profundidade de 4,35 m em Neossolo Quartzarênico Distrófico, 4,30 m em Neossolo Quartzarênico Álico e 2,77 m em Latossolo Vermelho Eutrófico. Entre os solos Podzólicos (nomenclatura antiga), a maior profundidade com potencial de ser atingida foi de 2,18 m, em Argissolo Vermelho Amarelo Distrófico.

Considerando que os lençóis subterrâneos na região são encontrados a partir de $1,5 \mathrm{~m}$ de profundidade e os resultados obtidos para tebuthiuron, constata-se que este princípio ativo apresenta maior tendência potencial ao risco de contato com o lençol nas áreas de cultivo de cana-de-açúcar sob três solos: Latossolo Vermelho Eutrófico, Neossolo Quartzarênico Distrófico e Neossolo Quartzarênico Álico; fato que se evidencia por meio dos valores de profundidade obtidos, cumulativamente, 
para o período de três anos, que mostram a tendência potencial da presença do produto no lençol dos três solos, mesmo que em níveis de concentração não prejudiciais à saúde (conforme as recomendações da "Drinking Water Directive 89/778/EEC", ou seja, que é de $0,1 \mu \mathrm{g} \mathrm{L}^{-1}$ por agrotóxico e de $0,5 \mu \mathrm{g} \mathrm{L}^{-1}$ para a soma de componentes). Acrescenta-se, contudo, que o simulador utilizado não oferece a possibilidade de investigação de reaplicações consecutivas do produto no mesmo cenário.

Os valores semelhantes encontrados para as concentrações finais do produto nos diferentes solos são explicados em função da adoção de um mesmo valor de $t_{1 / 2}$ para o produto utilizado para todos os tipos de solo estudados, devido a ausência de dados calculados para cada solo. Os teores reduzidos de carbono orgânico, para Latossolo Vermelho Eutrófico, Neossolo Quartzarênico Distrófico e Neossolo Quartzarênico Álico, respectivamente, aliados aos baixos teores de argila de alta atividade, podem ter sido os fatores responsáveis pela descida mais rápida do tebuthiuron. Acrescentese a isso, a própria característica do tebuthiuron que, normalmente, possui baixo poder de adsorção em solos arenosos (Mello Filho et al., 1985).

Esses resultados reforçam aqueles obtidos por Pessoa et al. (1998) em estudos de simulação do comportamento do tebuthiuron em Areia Quartzosa, na região de Ribeirão Preto, SP, e corroboram com os fatores carbono orgânico e argila do solo, como decisivos na influência sobre a mobilidade do tebuthiuron. A tendência de lixiviação apresentada pelo tebuthiuron também está em conformidade com as apresentadas para o herbicida pela US-EPA-Environmental Protection Agency, que o apresenta como um dos produtos de maior potencial de lixivação para água subterrânea (http:// www.bae.ncsu.edu/programs/extension/publicat/wqwm/ re10.html; consultado em 29/10/2002)

\section{Banana}

Os resultados obtidos pelas simulações realizadas para o inseticida aldicarb, utilizado na cultura de banana, em solos predominantes no Submédio São Francisco, próximos a Petrolina, PE, são apresentados na Tabela 5.

Nas simulações realizadas para aldicarb em banana, percebese que:

a) primeiro ano: a quantidade de produto presente no solo foi de $0,19 \mathrm{~g}$ por cova; registrou-se um potencial para alcançar as profundidades de 1,32 m, em Neossolo Quartzarênico Álico, 0,83 m em Neossolo Quartzarênico Distrófico, e 0,68 m em Latossolo Vermelho Eutrófico. Entre os solos Podzólicos (nomenclatura antiga) a maior profundidade com potencial a ser atingida foi de 0,54 m, em Argissolo Vermelho Amarelo Distrófico;

b) segundo ano: a quantidade de produto no solo foi de 4,2 x $10^{-5}$ g por cova; registrou-se o potencial para alcançar profundidades de 3,69 m em Neossolo Quartzarênico Distrófico; 3,64 m em Neossolo Quartzarênico Álico e 2,35 m em Latossolo Vermelho Eutrófico. Entre os solos Podzólicos (nomenclatura antiga) a maior profundidade com potencial de ser atingida foi de 1,889 m, em Argissolo Vermelho Amarelo Distrófico;
Tabela 5. Valores de profundidades (Prof) e de quantidades (Qtd) de aldicarb encontradas ao final de cada ano de simulação em diferentes solos

\begin{tabular}{ccc}
\hline \multirow{2}{*}{ Solo } & \multicolumn{2}{c}{ Aldicarb } \\
\cline { 2 - 3 } & $\begin{array}{c}\text { Prof. } \\
(\mathrm{m})\end{array}$ & $\begin{array}{c}\text { Qtd } \\
\left(\mathrm{g} \mathrm{cova}^{-1}\right)\end{array}$ \\
\hline
\end{tabular}

$$
\text { A. Primeiro ano }
$$

Latossolo Amarelo Distrófico

Latossolo Amarelo Eutrófico

Latossolo Vermelho Eutrófico

Argissolo Vermelho Amarelo Distrófico

Argissolo Vermelho Amarelo Eutrófico

Argissolo Amarelo Álico

Argissolo Amarelo Distrófico

Argissolo Amarelo Eutrófico

Argissolo Acinzentado Álico

Planossolo Eutrófico

Neossolo Quartzarênico Distrófico

Neossolo Quartzarênico Álico

$$
\text { B. Segundo ano }
$$

Latossolo Amarelo Distrófico

Latossolo Amarelo Eutrófico

Latossolo Vermelho Eutrófico

Argissolo Vermelho Amarelo Distrófico

Argissolo Vermelho Amarelo Eutrófico

Argissolo Amarelo Álico

Argissolo Amarelo Distrófico

Argissolo Amarelo Eutrófico

Argissolo Acinzentado Álico

Planossolo Eutrófico

Neossolo Quartzarênico Distrófico

Neossolo Quartzarênico Álico

$$
\text { C. Terceiro ano }
$$

Latossolo Amarelo Distrófico

Latossolo Amarelo Eutrófico

Latossolo Vermelho Eutrófico

Argissolo Vermelho Amarelo Distrófico

Argissolo Vermelho Amarelo Eutrófico

Argissolo Amarelo Álico

Argissolo Amarelo Distrófico

Argissolo Amarelo Eutrófico

Argissolo Acinzentado Álico

Planossolo Eutrófico

Neossolo Quartzarênico Distrófico

Neossolo Quartzarênico Álico

$0,4151,9 \times 10^{-1}$

$0,4451,9 \times 10^{-1}$

$0,6791,9 \times 10^{-1}$

$0,5411,9 \times 10^{-1}$

$0,3671,9 \times 10^{-1}$

$0,5161,9 \times 10^{-1}$

$0,3461,9 \times 10^{-1}$

$0,4091,9 \times 10^{-1}$

$0,5291,9 \times 10^{-1}$

$0,3641,9 \times 10^{-1}$

$0,8321,9 \times 10^{-1}$

$1,3201,9 \times 10^{-1}$

$1,5684,2 \times 10^{-5}$

$1,778 \quad 4,2 \times 10^{-5}$

$2,350 \quad 4,2 \times 10^{-5}$

$1,8894,2 \times 10^{-5}$

$1,4224,2 \times 10^{-5}$

$1,7854,2 \times 10^{-5}$

$1,5924,2 \times 10^{-5}$

$1,6674,2 \times 10^{-5}$

$1,6364,2 \times 10^{-5}$

$1,1944,2 \times 10^{-5}$

$3,6874,2 \times 10^{-5}$

$3,640 \quad 4,2 \times 10^{-5}$

$2,000 \quad 6,5 \times 10^{-9}$

$2,440 \quad 6,5 \times 10^{-9}$

$3,270 \quad 6,5 \times 10^{-9}$

$2,710 \quad 6,5 \times 10^{-9}$

$2,040 \quad 6,5 \times 10^{-9}$

$2,5206,5 \times 10^{-9}$

$2,336 \quad 6,5 \times 10^{-9}$

$2,460 \quad 6,5 \times 10^{-9}$

$2,210 \quad 6,5 \times 10^{-9}$

$1,6906,5 \times 10^{-9}$

$5,560 \quad 6,5 \times 10^{-9}$

$5,110 \quad 6,5 \times 10^{-9}$

c) terceiro ano: a quantidade de produto no solo foi de 6,5 x $10^{-9} \mathrm{~g}$ por cova; evidenciou-se o potencial para alcançar profundidades de 5,56 m em Neossolo Quartzarênico Distrófico, 5,11 m em Neossolo Quartzarênico Álico e 3,27 m em Latossolo Vermelho Eutrófico. Entre os solos Podzólicos (nomenclatura antiga) a maior profundidade com potencial a ser atingida foi de 2,71 m, em Argissolo Vermelho Amarelo Distrófico.

Os valores semelhantes, encontrados para as concentrações finais do produto nos diferentes solos, podem ser explicados em função da adoção de um mesmo valor de t/1/2 para o produto, utilizado em todos os cenários de tipos de solo estudados, dada a ausência também, para aldicarb, de dados calculados em cada tipo de solo, conforme já salientado também para o tebuthiuron. As quantidades remanescentes do produto 
também estão abaixo daquelas consideradas nocivas à saúde humana, no que se refere a qualidade da água para consumo (conforme as recomendações da "Drinking Water Directive 89/778/EEC", ou seja, que é de $0,1 \mu \mathrm{g} \mathrm{L}^{-1}$ por agrotóxico e de $0,5 \mu \mathrm{g} \mathrm{L}^{-1}$ para a soma de componentes). Deve ser levado em consideração, para fim dos resultados apresentados neste trabalho, que o simulador utilizado não oferece a possibilidade de investigação de reaplicações consecutivas do produto no mesmo cenário.

Os resultados obtidos corroboram com os apresentados em Guenzi (1974), que indica a rápida degradação do aldicarb no solo. O mesmo autor informa também que o produto sofre perda por volatilização, o que pode ser fator relevante na região semi-árida, ante as altas temperaturas médias predominantes. Assim os resultados obtidos pelas simulações precisam ser validados para condições de campo do Nordeste brasileiro.

A tendência de lixiviação apresentada pelo aldicarb também está em conformidade com as informações obtidas para o produto junto a US-EPA-Environmental Protection Agency, que o apresenta como estando entre os de maior potencial de lixivação para água subterrânea (http://www.bae.ncsu.edu/ programs/extension/publicat/wqwm/re10.html; consultado em 29/10/2002).

\section{CONCLUSÕES}

1. O tebuthiuron apresentou maior potencial de risco de presença de concentrações do produto em níveis que merecem ser investigados em monitoramentos "in loco", nos solos Latossolo Vermelho Eutrófico, Neossolo Quartzarênico Distrófico e Neossolo Quartzarênico Álico, dada a sua maior persistência e mobilidade a partir do segundo ano da aplicação e a localização dos lençóis na região.

2. O aldicarb apresentou maior mobilidade inicial, intensificada a partir do segundo ano depois da aplicação, e menor tendência a risco a partir do segundo ano, onde as concentrações remanescentes são praticamente nulas.

3. As concentrações finais obtidas pelas simulações para os produtos indicam tendências de estarem abaixo daquelas que oferecem risco à saúde humana, segundo limites estabelecidos nas recomendações da "Drinking Water Directive 89/ 778/EEC", dada a inexistência de valores referencia similares para o nosso país para os princípios ativos estudados.

\section{LITERATURA CITADA}

Altenburger, R. Pesticides in EC drinking water - limit value may be raised. Pestizid Brief, PAN Germany, October 1993.

BRASIL. Brasil e a certificação ISO9000. Brasília: Ministério da Indústria, do Comércio e do Turismo- MICT, 1996. 24p.

Cerdeira, A.L.; Gomes, M.A.F.; Pessoa, M.C.P.Y.; Bonato, P.S.; Lanchote, V.L. Tebuthiuron in soil and groudwater in sugarcane area in Brazil. Bollettino dei Chimici Igienisti, Milano, v.51, n.4, p.51-57, 2000.
CODEVASF - Companhia de Desenvolvimento do Vale do São Francisco - $3^{\text {a }}$ Superintendência Regional. Monitoramento dos ambientes aquáticos para a preservação ambiental dos cursos d'água no Projeto de Irrigação Senador Nilo Coelho, Madre Tereza, Petrolina/PE. Petrolina: CODEVASF, Relatório Trimestral 1, julho/1998.

EMBRAPA - Empresa Brasleira de Pesquisa Agropecuária. Centro Nacional de Pesquisa de Solos. Sistema brasileiro de classificação de solos. Brasília: Embrapa Produção da Informação; Rio de Janeiro: EMBRAPA Solos, 1999. 412p.

Ferracini, V.L.; Pessoa, M.C.Y.P.; Silva, A. de S., Spadotto, C.A. Análise de risco de contaminações das águas subterrâneas e superficiais da Região de Petrolina/PE e Juazeiro/BA. Pesticidas: Revista Ecotoxicologia e Meio Ambiente, Curitiba, v.11, 2001.

Guenzi, W.D. (ed.) Pesticides in soil and water. Madison: Soil Science Society of America, 1974. 562p.

Mello Filho, A.T. de; Rocha, C.L.; Silva, S.A da; Honda, T. Estudo de lixiviação e degradação de tebuthiuron em solos dos estados de São Paulo e Alagoas. Stab, 5p., n.2, p.47-51, 1985.

Nofziger, D.L; Hornsby, A G. CMLS-94- Chemical movement in layered soils. Gainsville: University of Florida, Department of Agronomy, 1994. 76p.

Paranhos, S.B. Cana-de-açúcar: cultivo e utilização. Campinas: Fundação Cargil , 2v., 1987. 856p.

Pessoa, M.C.P.Y.; Gomes, M.A.F.; Dornelas de Souza, M.; Cerdeira, A.L.; Nicolella, G.; Monticelli, A. Simulação do movimento de herbicidas utilizados no monocultivo de canade-açúcar em Areia Quartzosa da área de recarga do Aquífero Guarani (antigo Botucatu) em Ribeirão Preto, SP. Revista Científica Rural, Bagé, v.3, n.2, p.11-19. 1998.

Pessoa, M.C.P.Y; Luchiari Júnior, A ; Fernandes, E.N.; Lima, M. A. de. Principais modelos e simuladores usados em análise de impacto ambiental da agricultura. Jaguariúna: EMBRAPA-CNPMA, 1997. 87p. Documentos, n. 8

Pessoa, M.C.P.Y.; Silva, A. de S.; Camargo, C.P. Qualidade e certificação de produtos agropecuários. Brasília: EMBRAPA Informação Tecnológica, 2002. 188p. Texto para Discussão, 14

Rodrigues, B. N; Almeida, F.S. Guia de herbicidas. 3. Londrina: Ed. Londrina, $1995.675 \mathrm{p}$.

SEBRAE - Serviço de Apoio a Micro e Pequenas Empresas. A questão ambiental e as empresas. Brasília, 1998, 240p. Meio Ambiente e a Pequena Empresa

Silva, A. de S.; Hermes, L.C.; Freire, L.C.L.; Coelho, P.R.; Pessoa, M.C.P.Y. Qualidade ambiental e produção integrada de frutas (PIF) no sub-médio do Rio São Francisco, Petrolina (PE) e Juazeiro (BA), Brasil. In: Seminário Brasileiro de Produção Integrada de Frutas, 2. Resumos... Bento Gonçalves: EMBRAPA Uva e Vinho, 2000. p.1-8.

Soares, J.M.; Santos, C.R. dos. Manejo de irrigação de frutíferas. Petrolina: EMBRAPA - CPATSA, 1998, 26p. 